\title{
Prosumers knowledge sharing to develop and manage products
}

Ewa Ziemba, Faculty of Finance and Insurance, University of Economics in Katowice, Poland, ewa.ziemba@ue.katowice.pl

Monika Eisenbardt, Faculty of Finance and Insurance, University of Economics in Katowice, Poland, monika.eisenbardt@ue.katowice.pl

Roisin Mullins, Faculty of Business and Management, University of Wales Trinity Saint David, United Kingdom, r.mullins@uwtsd.ac.uk

Dariusz Grabara, Faculty of Finance and Insurance, University of Economics in Katowice, Poland, dariusz.grabara@ue.katowice.pl

\begin{abstract}
The purpose of this paper is to advance research on prosumers knowledge sharing with enterprises and public organizations by examining as well as improve the understanding of what knowledge about products, prosumers share and would like to share in order to improve products. This paper provides and verifies a new theoretical framework depicting prosumers knowledge about products, which they can share with business and public organizations. The reported outcomes are the result of a questionnaire survey that yielded responses from 783 Poland and 171 United Kingdom (UK) based prosumers. The research findings reveal that prosumers mainly share their knowledge about products functionality, ease and intuitiveness of use, as well as a products reliability and durability, whereas they rarely share knowledge related to products design or the packaging of products. It is also found that there are significant differences between knowledge about products that prosumers share and would like to share. In addition, Poland prosumers share and would like to share various kinds of knowledge about products more frequently than UK based prosumers.
\end{abstract}

Keywords: Consumer knowledge, prosumer, knowledge sharing, product development, prosumers in Poland, prosumers in UK.

\section{Introduction}

Modern consumers are not just passive users of products or services anymore, more consumers engage in creating, designing, and even developing products (Aghamirian, Dorri, \& Aghamirian, 2013). This is made possible through knowledge sharing. Through undertaking some business tasks and taking part in business projects aimed at consumers, they share knowledge with enterprises and other consumers (Löcker et al., 2014). These consumers' activities have changed their role in business-consumers relationships (Calosci, 2017). In turn, consumers who are active participants of the knowledge exchange process and who share knowledge with enterprises or other consumers are known as prosumers. The term prosumer is directly connected with a prosumption term, which means the process in which prosumers actively share knowledge with enterprises or other prosumers (Bylok, 2013; Fine, Gironda, \& Petrescu, 2017; HernándezSerrano, Renés-Arellano, Graham, \& Greenhill, 2017; Rayna \& Striukova, 2016; Ritzer \& 
Jurgenson, 2010; Tapscott \& Williams, 2006; Xie, Bagozzi, \& Troye, 2008). In general, prosumption refers to prosumers' activities, which they undertake to produce things of value for enterprises, as well as for themselves.

For modern enterprises knowledge is valued as a strategic advantage that helps them maintain their market competitiveness. Moreover it helps them invest in research and development from knowledge sharing with prosumers, which is essential, while continue to develop themselves to become more responsive to customer needs (Aghamirian, Dorri, \& Aghamirian, 2013; Brabham, 2012; Tsai, Tsai, Li, \& Lin, 2012; Tseng, 2016; Song \& Kang, 2016). Knowledge is created inside a particular enterprise (Nonaka \& Takeuchi, 2000). However, more companies that focus on external knowledge sources are recognising that consumers' knowledge have become elevated as one of the most important intangible assets for enterprises (Planells, 2015; Ziemba \& Mullins, 2016).

Also while there is still much research being undertaken to analyse knowledge culture and determine frameworks to diagnose knowledge culture (De Long, 1997; Gold, Malhotra, \& Segars, 2001; Kayworth \& Leidner, 2003), it is clear that cultural perspectives must be considered across country boundaries when capturing prosumer perspectives on products and services for the current and future marketplace. Furthermore, Glisby (2003) suggested that culture influences knowledge sharing and is associated with the learning processes in Nonaka's Socialization, Externalization, Combination and Internalization (SECI) model, which also affect the social interaction of certain forms of knowledge sharing. However, this study of Polish and UK-based prosumers is mindful of these culturally determined conditions.

Sharing knowledge in the role of a prosumer can play a vital role in the whole product's life cycle as they participate in the process as co-creators or even co-producers of products (Ritzer \& Jurgenson, 2010; Tapscott \& Williams, 2006). Xie, Bargozzi, and Troye (2008) acknowledged that resulting from knowledge sharing, prosumers can use products that more closely fit to their expectations and needs. Thus, prosumers knowledge can be embedded into the business process, especially those of them that are connected with development of products (Aghamirian, Dorri, \& Aghamirian, 2015; Trejo, Gutiérrez, \& Guzman, 2016). Ziemba and Eisenbardt (2015) explained the basis of the American Productivity and Quality Center (APQC)'s Process Classification Framework (APQC, 2016), and proposed a conceptual framework of prosumers participation in business processes. The framework embraces four operational processes in which prosumers' knowledge can be notably used, such as: Process 2.0 Develop and Manage Products and Services; Process 3.0 Market and Sell Products and Services; Process 4.0 Deliver Products and Services; and Process 5.0 Manage Customer Service. Their research indicated that prosumers mainly share knowledge for development of products suggesting the close connections to business process 2.0 Develop and Manage Products and Services (Ziemba \& Eisenbardt, 2017). Table 1 indicates the kinds of prosumers knowledge connected with business process 2.0.

A better understanding of how prosumers share their knowledge for development of products requires a new approach which focuses on each particular kind of prosumers knowledge in detail. Thus, this paper aims to answer the research question of what kind of knowledge about products do Poland and UK based prosumers share and would like to share? Accordingly, the objectives of the paper are threefold. First, identified business processes in which prosumers can share knowledge, and, in turn, indicate the kinds of knowledge which prosumers share about 
Table 1: Kinds of Knowledge That Prosumers Can Share About Products (APQC, 2016; Ziemba \& Eisenbardt, 2015)

\begin{tabular}{|c|l|}
\hline Item & Kind of Knowledge Prosumers Can Share About Products \\
\hline K1 & New product design (i.e. shape or colour of the product) \\
\hline K2 & $\begin{array}{l}\text { Materials from which the product was made (materials of a type from which the product should be } \\
\text { produced) }\end{array}$ \\
\hline K3 & Package or graphic elements of the product (i.e. logo or label) \\
\hline K4 & Product functionality \\
\hline K5 & Reliability and durability of the product \\
\hline K6 & Ease and intuitiveness of product use \\
\hline
\end{tabular}

products. Second, performed a thorough analysis, to determine what knowledge about products prosumers share and would like to share. Finally, investigated the different kinds of knowledge about products that prosumers share and would like to share, as well as considering the differences between Poland and United Kingdom (UK) based prosumers. Hence, this study tests whether there are statistically significant differences between knowledge about products that Poland and UK based prosumers share, and similarly whether there are statistically significant differences between knowledge about products that Poland and UK based prosumers would like to share. In practical terms, enterprises gain new insight from these findings with specific reference to Poland and UK based prosumers knowledge sharing about products what may help them to make decisions about which projects and activities they can engage with prosumers for future knowledge sharing. This paper is organized as follows: the research questions and hypotheses followed by the research methodology; then results, analysis, and discussion are provided; while the paper concludes with a summary, limitations, and avenues for future research.

\section{Research Questions and Hypotheses}

Detailed analysis of the literature shows that many researchers have recognized the fact that knowledge is crucial for modern enterprises' performance and development. There are two main paradigms to the application of knowledge and innovations in enterprises: closed and open innovation (Chesbrough, 2006). The former means that the knowledge is created mainly inside of an enterprise. The recognition of different types of innovation referred to in this paradigm intensify our view that organizations tend to fall into the closed innovation cycle that we feel present a substantial flaw to the business - i.e. when a skilled and knowledgeable employee leaves an enterprise s/he takes a good deal of that knowledge with them to their new employer. That is why more and more enterprises focus on external sources of knowledge that include knowledge about, for, and from prosumers (Ziemba, Eisenbardt, \& Mullins, 2017). Many enterprises have noticed that the latter - the open innovation paradigm emphasis that they can and should use external ideas and knowledge in the combination with internal ones (Walsh, Lee, \& Nagaoka, 2016). It means that they should and even must consider prosumers knowledge as external source of ideas and innovations. Nonetheless, just a few academics focus on the possibilities of employing external knowledge sources among which prosumers' knowledge has 
become more essential (Cui \& Wu, 2015; Geri, Gafni, \& Bengov, 2017; Panni, 2015; Taherparvar, Esmaeilpour, \& Dostar, 2014).

We revealed that despite the wealth of literature on knowledge management, as well as the increasingly growing literature on prosumption, the association between business processes development and prosumers knowledge remains largely unexplored and poorly understood. Some researchers have considered that efficient business processes management is crucial for enterprises and could bring rational consequences (Aghamirian, Dorri, \& Aghamirian, 2015; Kania, 2012; Trejo, Gutiérrez, \& Guzman, 2016). While others presented research outcomes, which show that prosumers can share knowledge about products and at the same time have an impact on products development (Ziemba \& Eisenbardt, 2015, 2015a), however, their participants were from Poland prosumers only. Therefore, their findings are a particular view of Poland prosumers on knowledge sharing with enterprises. After an extensive review of the literature, we were unable identify any detailed study concerning business processes development, especially products development, and prosumers' knowledge sharing. Furthermore, we have not found papers that focused on comparison of different countries in that matter. Carrying out the research between Poland and UK based prosumers may contribute to greater understanding of prosumers' knowledge sharing for products development and could help fill the gap in the existing body of knowledge. This paper focuses on addressing the following research questions:

RQ1: What knowledge about products do Poland and UK based prosumers (combined) share?

RQ2: What knowledge about products would Poland and UK based prosumers (combined) like to share?

RQ3: Are there statistically significant differences in knowledge about products that Poland and UK based prosumers (combined) share and would like to share?

RQ4: What knowledge about products do Poland prosumers share?

RQ5: What knowledge about products do UK based prosumers share?

RQ6: Are there statistically significant differences in knowledge about products that Poland and UK based prosumers share?

RQ7: What knowledge about products would Poland prosumers like to share?

RQ8: What knowledge about products would UK based prosumers like to share?

RQ9: Are there statistically significant differences in knowledge about products that Poland and UK based prosumers would like to share?

Taking into account all above considerations and the above research questions, three research hypotheses were formulated:

H1: There are statistically significant differences in knowledge about products that Poland and UK based prosumers (combined) share and would like to share.

H2: There are statistically significant differences in knowledge about products that Poland and UK based prosumers share.

H3: There are statistically significant differences in knowledge about products that Poland and UK based prosumers would like to share. 
Figure 1 depicts the graphical combination of research questions with research hypotheses posed for knowledge sharing about products.

\begin{tabular}{|l||l|l|}
\hline RQ1 & \\
\hline \hline RQ2 & & \\
\hline \hline RQ3 & & \\
\hline \hline RQ4 &
\end{tabular}

Figure 1: Graphical Combination of the Research Questions with Research Hypotheses.

Figure 1 shows that each posited hypothesis was supported by three research questions. That approach enabled us to confirm or to reject the hypotheses and as a result led us to the answer to the main research question.

\section{Research Methodology}

Research methods included a critical review of the literature, logical deduction, case studies, a survey questionnaire, and statistical analysis. The research process took the following steps:

Literature: A critical review of existing studies related to 'prosumption', 'prosumer', 'customer', 'consumer', 'knowledge sharing', 'business processes', and 'products development' enabled examination of prosumers knowledge sharing to develop and manage products. The review embraces four bibliographic databases: Ebsco, ProQuest, Emerald Management, and ISI Web of Knowledge. In addition, some journals and Web materials dedicated to research on 'consumption' and 'prosumption' were also explored.

Case Studies: Case studies of prosumers' knowledge sharing indicated that prosumers can share their knowledge and at the same time they can develop and manage products (Ziemba \& Eisenbardt, 2015). Based on the analysis of literature, as well as the analysis of the above mentioned case studies, the specific kinds of knowledge that they can share about products were proposed.

Pilot: An initial pilot survey instrument was designed in Polish for the Polish participants and translated into English for the UK participants. The English translation was undertaken in Poland and the survey instrument was evaluated and pretested with colleagues and a sample of respondents in the UK University to determine suitability and appropriateness for the survey. The survey instrument was divided into two parts. After a few demographics questions all participants were obliged to answer the question: Have you ever assessed or commented on products or companies, proposed products improvements to the companies or designed new 
products? This question enabled the division of respondents into consumers (not active in this area) and prosumers (active ones). The survey instrument contained questions concerning specified kinds of knowledge that prosumers can share. The questions were: (1) Please indicate, what were your assessments or comments on products or proposals of product development concerns? (2) If you could, in a free and unlimited way, share your knowledge about products, propose ideas of products developments or ideas for the design of new products - please indicate what would your proposals be concerned with? The former question was directed only to prosumers. The latter was directed to both - consumers and prosumers. The kinds of knowledge about products were listed for these questions (see Table 1). For each listed kind of knowledge the respondents could choose one of five responses, according to a 5-point Likert scale: (1) definitely no, (2) rather no, (3) neither yes nor no, (4) rather yes, (5) definitely yes. In November 2014, the more in-depth pilot survey was conducted in Poland. The purpose was substantive and methodological scrutiny of the questionnaire. To conduct reliability analysis, Cronbach's coefficient Alpha was used. For all analyzed items the Cronbach's Alpha was 0.881. According to Hinton (2004), it can be concluded that the scale had high reliability, and it could be used in the research process. Moreover, substantive scrutiny of the survey instrument enabled to perform minor changes to improve the quality of the survey.

CAWI: Applying the Computer-Assisted Web Interview (CAWI) method and employing the Poland platform Ankietka.pl, and the UK platform Bristol Online Survey (BOS), hosted at the University of Bristol, the survey instrument was uploaded to the website. Data collection took place between the end of December 2014 and March 2015 in Poland, and between February and April 2016 in the UK. In Poland, the designed sample size was 2,500 people, comprising people of different age, gender, and Information and Communication Skills (ICT) skills. In the UK, the online survey letter and URL was initially posted to 1,000 individuals comprising people of different age, gender, and ICT skills, as well as presented to a random sample of the target population. Using online tools permits contact with an accessible audience as the survey appears on search engine lists due to metatags and appropriate placing of keywords. After screening the responses and excluding outliers, there was a final research sample of 783 usable, correct and complete questionnaires from Poland and 171 from the UK. The demographic analysis of the research sample is presented in Table 2 .

Reliability: As the process of collecting data was completed, the reliability was calculated. The Cronbach's Alpha coefficient with all seven items confirmed a high internal consistency (0.86). In addition, it was determined that the removal of some items would not lead to the significant improvement of internal consistency among items on the scale. Therefore, it was decided that for further analyses all seven items would be used.

Statistical Analyses: In order to answer the research questions and confirm the research hypotheses, statistical analysis was employed. Firstly, the descriptive analysis was employed to describe the knowledge that prosumers share and would like to share about products. The following statistics were calculated: mean, median (MDN), mode, standard deviation (SD), coefficient of variation (CV), and skewness (SK). Secondly, the Mann-Whitney U test was applied in order to identify differences between Poland and UK based prosumers, and between the knowledge that prosumers share and would like to share. This test was selected because it does not assume any assumptions related to the distribution, and it is used to test whether two 
independent samples of observations are drawn from the same or identical distribution. The statistical analysis was made using Microsoft ${ }^{\circledR}$ Excel and Statistica $^{\circledR}$ (ver.13.1) software.

Table 2: Demographic Analysis of the Research Participants (N=954)

\begin{tabular}{|c|c|c|c|c|}
\hline \multirow[b]{2}{*}{ Demographic profile } & \multicolumn{2}{|c|}{ Poland $\left(\mathrm{n}_{1}=783\right)$} & \multicolumn{2}{|c|}{ United Kingdom $\left(\mathrm{n}_{2}=171\right)$} \\
\hline & $\begin{array}{l}\text { Number of } \\
\text { Participants }\end{array}$ & Percentage & $\begin{array}{l}\text { Number of } \\
\text { Participants }\end{array}$ & Percentage \\
\hline \multicolumn{5}{|l|}{ Gender } \\
\hline Female & 599 & $76.5 \%$ & 98 & $57.3 \%$ \\
\hline Male & 184 & $23.5 \%$ & 73 & $42.7 \%$ \\
\hline \multicolumn{5}{|l|}{ Age } \\
\hline Builders generation: over 65 years old & 14 & $1.8 \%$ & 8 & $4.68 \%$ \\
\hline Baby-Boomers generation: $51-65$ years old & 35 & $4.5 \%$ & 25 & $14.62 \%$ \\
\hline X generation: $36-50$ years old & 108 & $13.8 \%$ & 67 & $39.18 \%$ \\
\hline Y generation: $21-35$ years old & 369 & $47.1 \%$ & 68 & $39.77 \%$ \\
\hline $\mathrm{Z}$ generation: less than 21 years old & 257 & $32.8 \%$ & 3 & $1.75 \%$ \\
\hline \multicolumn{5}{|l|}{ Level of education } \\
\hline higher education & 217 & $27.7 \%$ & 89 & $52.05 \%$ \\
\hline secondary education & 559 & $71.4 \%$ & 75 & $43.86 \%$ \\
\hline less than secondary education & 7 & $0.9 \%$ & 7 & $4.09 \%$ \\
\hline \multicolumn{5}{|l|}{ Place of residence } \\
\hline city with a population of more than 100,000 & 419 & $53.5 \%$ & 96 & $56.14 \%$ \\
\hline city with a population of less than 100,000 & 244 & $31.2 \%$ & 53 & $30.99 \%$ \\
\hline rural area & 120 & $15.3 \%$ & 22 & $12.87 \%$ \\
\hline
\end{tabular}

\section{Research Findings}

\section{Knowledge About Products that Poland and UK Based Prosumers (Combined) Share and Would Like to Share}

The following research questions and hypothesis were posed related to a comparison between knowledge about products that Poland and UK based prosumers (combined) share and would like to share:

RQ1: What knowledge about products do Poland and UK based prosumers (combined) share?

RQ2: What knowledge about products would Poland and UK based prosumers (combined) like to share?

RQ3: Are there statistically significant differences in knowledge about products that Poland and UK based prosumers (combined) share and would like to share?

H1: There are statistically significant differences in knowledge about products that Poland and UK based prosumers (combined) share and would like to share.

In order to answer RQ1 and RQ2, a detailed analysis concerning knowledge about products that Poland and UK-based prosumers (combined) share and would like to share was completed. The results are presented in Table 3 . It is found that prosumers mainly share their knowledge about product functionality (Mean=3.63; $\mathrm{MDN}=4$; Mode=4), ease and intuitiveness of product use $($ Mean=3.55; $\mathrm{MDN}=4$; $\mathrm{Mode}=4$ ), and reliability and durability of the product (Mean=3.48; $\mathrm{MDN}=4$; Mode=4). Whilst they were rather reluctant or they were not encouraged by enterprises 
to share knowledge about new product design (Mean=2.72; MDN=2; Mode=2), as well as about package or graphic elements of the product (Mean=2.79; MDN=3; Mode=2). However, it is found that prosumers would like to share knowledge more widely than they are currently sharing. Especially they would like to share knowledge about ease and intuitiveness of product use (Mean=4; $M D N=4 ; M o d e=4)$, and product functionality (Mean=3.95; MDN=4; Mode=4). What is more, the greater difference between means values pertains to new product design, as well as materials from which the product was made, indicating that there is a group of prosumers who are not sharing knowledge about products, nonetheless having such opportunity they would like to be engage in knowledge sharing.

Table 3: Knowledge About Products that Poland and UK Based Prosumers (Combined) Share

\begin{tabular}{|c|c|c|c|c|c|c|c|c|c|c|c|c|}
\hline \multirow{2}{*}{ Item } & \multicolumn{6}{|c|}{ Prosumers Share Knowledge } & \multicolumn{6}{|c|}{ Prosumers Would Like to Share Knowledge } \\
\hline & Mean & MDN & Mode & SDV & CV & SK & Mean & MDN & Mode & SDV & $\mathbf{C V}$ & SK \\
\hline K1 & 2.72 & 2 & 2 & 1.26 & 0.47 & 0.57 & 3.50 & 4 & 4 & 1.19 & 0.34 & -0.42 \\
\hline $\mathrm{K} 2$ & 2.92 & 3 & 4 & 1.22 & 0.42 & -0.89 & 3.58 & 4 & 4 & 1.13 & 0.32 & -0.37 \\
\hline K3 & 2.79 & 3 & 2 & 1.24 & 0.44 & 0.64 & 3.19 & 3 & 4 & 1.18 & 0.37 & -0.68 \\
\hline K4 & 3.63 & 4 & 4 & 1.17 & 0.32 & -0.32 & 3.95 & 4 & 4 & 1.08 & 0.27 & -0.05 \\
\hline K5 & 3.48 & 4 & 4 & 1.23 & 0.35 & -0.42 & 3.87 & 4 & 4 & 1.14 & 0.29 & -0.11 \\
\hline K6 & 3.55 & 4 & 4 & 1.21 & 0.34 & -0.37 & 4.00 & 4 & 4 & 1.05 & 0.26 & 0.00 \\
\hline K7 & 3.41 & 4 & 4 & 1.25 & 0.37 & -0.47 & 3.82 & 4 & 4 & 1.12 & 0.29 & -0.16 \\
\hline
\end{tabular}

Abbreviations used: MDN - median, SD - standard deviation, CV - coefficient of variation, and SK - skewness

In order to answer RQ3 (Are there statistically significant differences between knowledge about products that Poland and UK based prosumers (combined) share and would like to share?), the Mann-Whitney U test was used. It was used since in this study, two independent samples were analyzed: (1) knowledge about products that prosumers share; and (2) knowledge about products that they would like to share. The analysis results presented in Table 4 show that there were significant differences $(\mathrm{p}<0.05)$ for all analyzed items. Thus, H1 was supported.

Table 4: The Mann-Whitney U test results for Knowledge About Products that Poland and UK Based Prosumers (Combined) Share and Would Like to Share

\begin{tabular}{|c|l|c|c|}
\hline Item & Types of Knowledge & $\mathbf{Z}$ & p value \\
\hline K1 & New product design & -10.356 & $<0.05$ \\
\hline K2 & Materials from which the product was made & -9.118 & $<0.05$ \\
\hline K3 & Package or graphic elements of the product & -5.472 & $<0.05$ \\
\hline K4 & Product functionality & -4.988 & $<0.05$ \\
\hline K5 & Reliability and durability of the product & -5.738 & $<0.05$ \\
\hline K6 & Ease and intuitiveness of product use & -6.479 & $<0.05$ \\
\hline K7 & Product performance & -5.649 & $<0.05$ \\
\hline
\end{tabular}

It was decided to perform detailed analysis of knowledge about products that Poland and UK based prosumers (combined) share as our intention was to draw a complete picture. The analysis was made using box plots. The results are presented in Figure 2. 

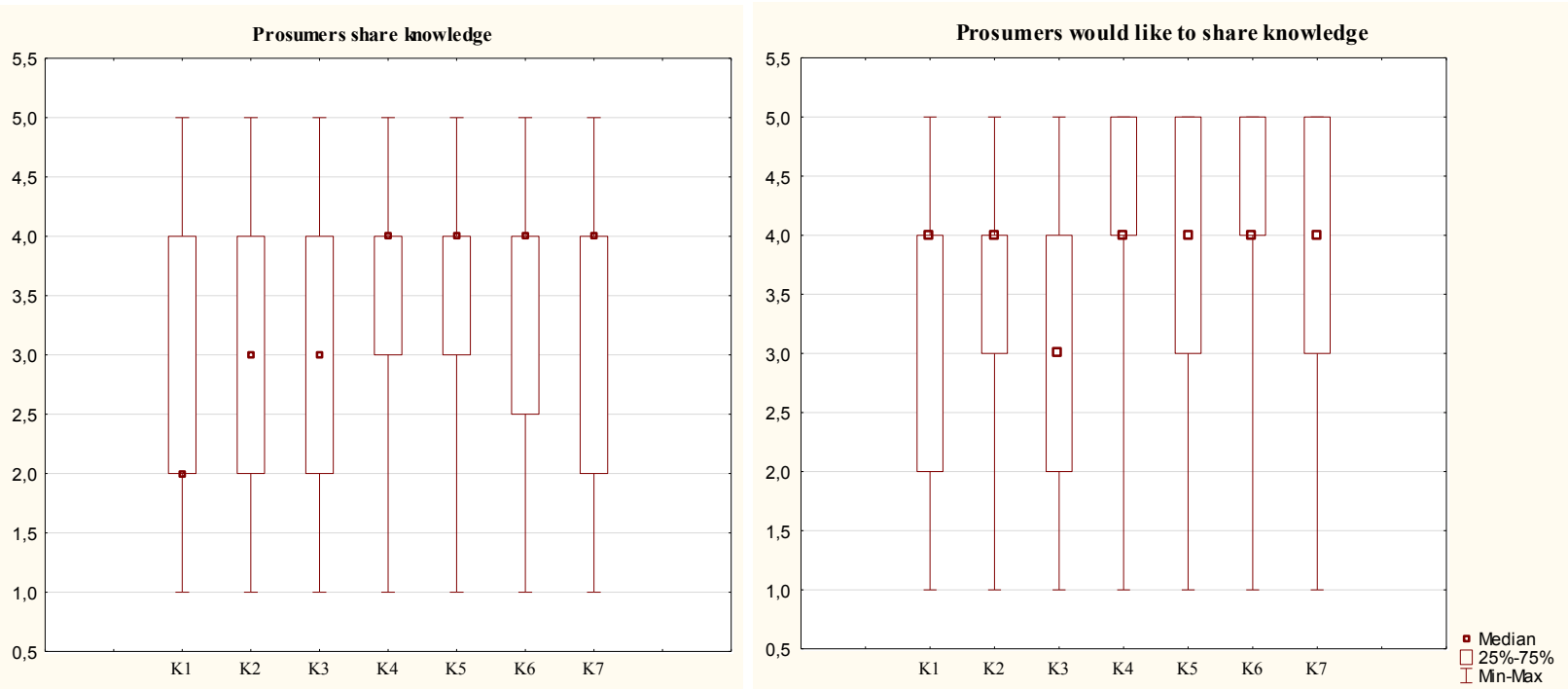

Figure 2: Knowledge About Products that Poland and UK Based Prosumers (combined) Share and Would Like to Share

The box plots presented in Figure 2 show that:

- There are median differences only in the case of new product design, as well as materials from which the product was made.

- In general, the values of the first quartile Q1 (25\%) are lower in the left box plot in comparison with the right box plot. It may suggest that prosumers would like to share knowledge about products, especially concerning the materials from which the product was made; product functionality; ease and intuitiveness of product use; as well as product performance, in improved ways than they are currently sharing.

- The values of the third quartile Q3 (75\%) in the left box plot do not exceed 4, whilst in the right box plot they exceed that value in four cases: product functionality; reliability and durability of the product; ease and intuitiveness of product use; as well as product performance. The results indicate that consumers would like to improve their shared knowledge in the future, particularly in those four kinds of knowledge K4, K5, K6 and $\mathrm{K} 7$. The language associated with these cases is highly technical, and as a cautionary note this may also result from self-selection bias of the respondents.

\section{Knowledge About Products that Poland and UK Based Prosumers Share}

The following research questions and hypothesis were posed related to a comparison in knowledge about products that Poland and UK based prosumers share:

RQ4: What knowledge about products do Poland prosumers share?

RQ5: What knowledge about products do UK based prosumers share?

RQ6: Are there statistically significant differences in knowledge about products that Poland and UK based prosumers share? 
H2: There are statistically significant differences in knowledge about products that Poland and UK based prosumers share.

Table 5: Knowledge About Products That Poland and UK Based Prosumers Share

\begin{tabular}{|c|c|c|c|c|c|c|c|c|c|c|c|c|}
\hline \multirow{2}{*}{ Item } & \multicolumn{5}{|c|}{ Polish Prosumers } & \multicolumn{6}{c|}{ UK-based Prosumers } \\
\cline { 2 - 16 } & Mean & MIDN & Mode & SDV & CV & SK & Mean & MDN & Mode & SDV & CV & SK \\
\hline K1 & 2.72 & 3 & 4 & 1.29 & 0.48 & -0.98 & 2.68 & 2 & 2 & 1.07 & 0.40 & 0.64 \\
\hline K2 & 2.94 & 3 & 4 & 1.24 & 0.42 & -0.85 & 2.76 & 2 & 2 & 1.09 & 0.40 & 0.70 \\
\hline K3 & 2.87 & 3 & 4 & 1.27 & 0.44 & -0.88 & 2.37 & 2 & 2 & 0.92 & 0.39 & 0.40 \\
\hline K4 & 3.76 & 4 & 4 & 1.11 & 0.30 & -0.21 & 2.93 & 2 & 2 & 1.17 & 0.40 & 0.80 \\
\hline K5 & 3.58 & 4 & 4 & 1.22 & 0.34 & -0.34 & 2.97 & 2.5 & 2 & 1.14 & 0.38 & 0.85 \\
\hline K6 & 3.67 & 4 & 4 & 1.18 & 0.32 & -0.28 & 2.96 & 2 & 2 & 1.17 & 0.40 & 0.82 \\
\hline K7 & 3.46 & 4 & 4 & 1.26 & 0.36 & -0.42 & 3.12 & 4 & 2 & 1.14 & 0.37 & 0.98 \\
\hline
\end{tabular}

Abbreviations used: MDN - median, SD - standard deviation, CV - coefficient of variation, and SK - skewness

In order to answer RQ4 and RQ5, a detailed analysis concerning knowledge about products that Poland and UK based prosumers share was completed. The results are presented in Table 5. It was found that Poland prosumers mainly share their knowledge about product functionality $(\mathrm{Mean}=3.76$; $\mathrm{MDN}=4$; Mode=4), ease and intuitiveness of product use (Mean=3.67; $\mathrm{MDN}=4$; Mode=4), and reliability and durability of the product (Mean=3.58; MDN=4; Mode=4). On the other hand, in general UK based prosumers are reluctant to share knowledge - the majority of the median and mode values are $2 \mathrm{~s}$, which means that they would rather not to share knowledge about products. If they do that, they only share knowledge about product performance (Mean=3.12; $M D N=4 ; M o d e=2)$. The general analysis of the results shows that Poland prosumers share knowledge more widely than UK based ones. Especially it is clearly visible in the case of product functionality, as well as ease and intuitiveness of product use, when the differences of median values are in the range of $2 \mathrm{~s}$.

In order to answer RQ6 (Are there statistically significant differences in knowledge about products that Poland and UK based prosumers share?), the Mann-Whitney U test was used. It was used since there were two independent samples: (1) Poland, and (2) UK based prosumers. The test results presented in Table 6 did not show any significant differences between Poland and UK-based prosumers except in two cases: new product design, and materials from which the product was made. Whereas there were significant differences in the case of package or graphic elements of the product, product functionality, reliability and durability of the product, ease and intuitiveness of product use, as well as product performance. Thus, H2 was partially supported.

It is striking that such little difference is observed in views of overall product design and the materials from which the product was made, K1 and K2. The original materials and overall product design are clearly not a substantial differentiating factor between the consumer groups of the two countries in this study. The p value results for $\mathrm{K} 3, \mathrm{~K} 4, \mathrm{~K} 5, \mathrm{~K} 6$ and $\mathrm{K} 7$ show there is less than $5 \%$ probability that the differences being observed is due to chance. The high $\mathrm{Z}$ values indicate a higher difference between Polish and UK prosumers especially K4 and K6, while these types of knowledge sharing about what the product does and how one uses it indicate clearly different attitudes in the two countries. 
Table 6: The Mann-Whitney U Test Results for Knowledge About Products That Poland and UK Based Prosumers Share

\begin{tabular}{|c|l|c|c|}
\hline Item & Types of Knowledge Shared & $\mathbf{Z}$ & p value \\
\hline K1 & New product design & -0.015 & 0.988 \\
\hline K2 & Materials from which the product was made & 1.158 & 0.247 \\
\hline K3 & Package or graphic elements of the product & 3.104 & $<0.05$ \\
\hline K4 & Product functionality & 5.119 & $<0.05$ \\
\hline K5 & Reliability and durability of the product & 3.916 & $<0.05$ \\
\hline K6 & Ease and intuitiveness of product use & 4.396 & $<0.05$ \\
\hline K7 & Product performance & 2.309 & $<0.05$ \\
\hline
\end{tabular}

It was decided to perform detailed analysis of knowledge about products that Poland and UK based prosumers share as our intention was to draw a whole picture in that matter. Also here, further analysis was made using box plots. The results are presented in Figure 3.

The box plots presented in Figure 3 show that:

- In all cases (despite product performance) the median values are higher in the case of Poland prosumers than UK based ones. The median values indicate that UK based prosumers do not have a strong preference to share knowledge about products - as the majority of them have median values of 2 .

- Three values of the first quartile Q1 (25\%) are higher in the case of Poland prosumers than UK based ones. This suggests that Poland prosumers share their knowledge about product functionality, reliability and durability of the product, and ease and intuitiveness of product use more often than UK based prosumers.
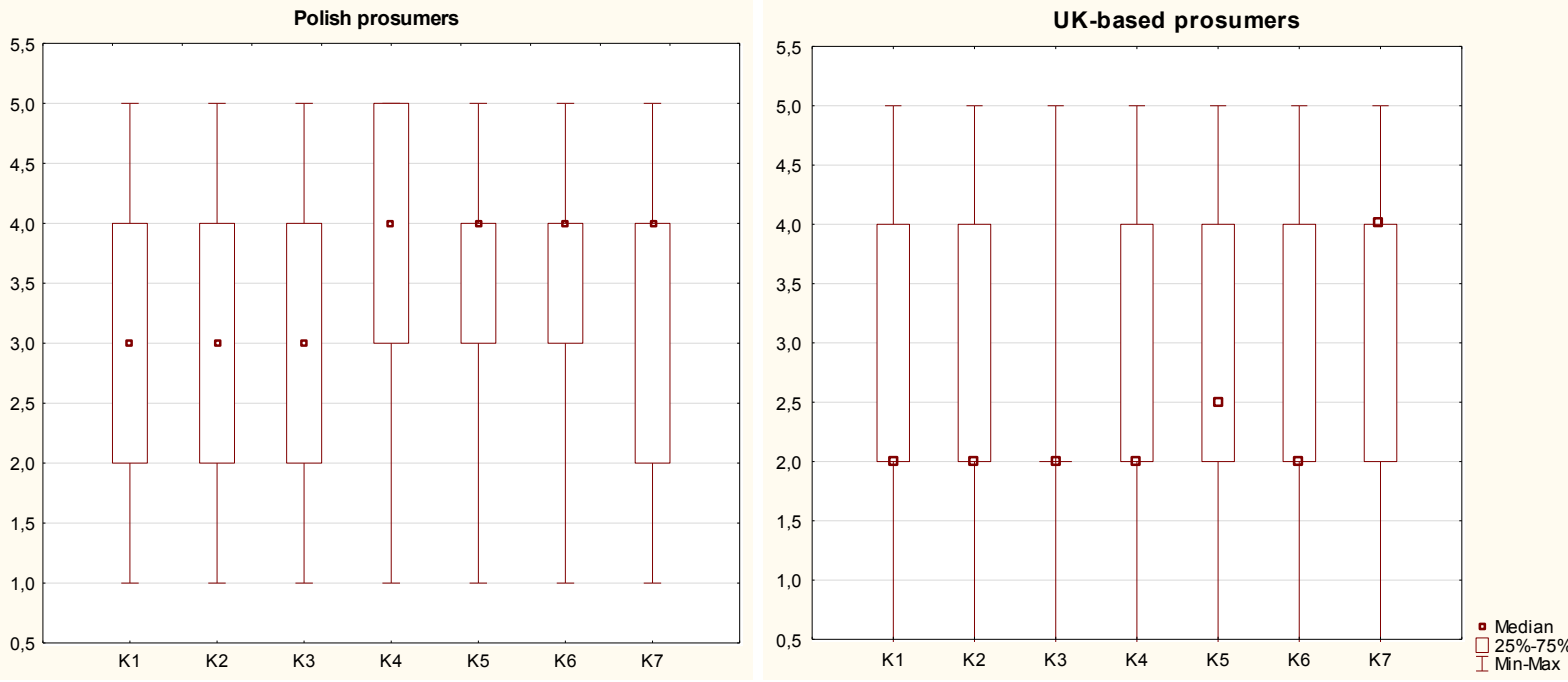

Figure 3: Knowledge about products which Poland and UK based prosumers share 


\section{Knowledge About Products That Poland and UK Based Prosumers Would Like to Share}

The following research questions and hypothesis related to a comparison in knowledge about products that Poland and UK based prosumers would like to share were posed:

RQ7: What knowledge about products would Poland prosumers like to share?

RQ8: What knowledge about products would UK based prosumers like to share?

RQ9: Are there statistically significant differences in knowledge about products that Poland and UK based prosumers would like to share?

H3: There are statistically significant differences in knowledge about products that Poland and UK based prosumers would like to share.

In order to answer the RQ7 and RQ8 a detailed analysis concerning knowledge about products that Poland and UK based prosumers would like to share was completed. The results are presented in Table 7. It is found that Poland prosumers would like to share their knowledge about ease and intuitiveness of product use (Mean=4.23; $\mathrm{MDN}=4$; Mode=5), product functionality $(\mathrm{Mean}=4.16 ; \mathrm{MDN}=4 ; \mathrm{Mode}=4)$, as well as product performance (Mean=4.04; $\mathrm{MDN}=4$; Mode $=4$ ). On the other hand, UK based prosumers are reluctant to share knowledge where the majority of the median and mode values are 2 , which means that they would not like to share knowledge about products. If they do they would like to share knowledge only about reliability and durability of the product (Mean=3.12; $M D N=4$; Mode=4). Nonetheless, the general analysis of the results shows that Poland prosumers would like to share knowledge more widely than UK based ones. It is clearly visible in case of: new product design, materials from which the product was made, package or graphic elements of the product, product functionality, as well as ease and intuitiveness of product use, when the differences of median values are equal to 2 .

Table 7: Knowledge About Products That Poland and UK Based Prosumers Would Like to Share

\begin{tabular}{|c|c|c|c|c|c|c|c|c|c|c|c|c|}
\hline \multirow{2}{*}{ Item } & \multicolumn{5}{|c|}{ Polish Prosumers } & \multicolumn{5}{c|}{ UK-based Prosumers } \\
\cline { 2 - 15 } & Mean & MDN & Mode & SDV & CV & SK & Mean & MDN & Mode & SDV & CV & SK \\
\hline K1 & 3.62 & 4 & 4 & 1.15 & 0.32 & -0.33 & 2.93 & 2 & 2 & 1.36 & 0.40 & 0.80 \\
\hline K2 & 3.71 & 4 & 4 & 1.09 & 0.29 & -0.27 & 2.98 & 2 & 2 & 1.30 & 0.38 & 0.86 \\
\hline K3 & 3.38 & 4 & 4 & 1.15 & 0.34 & -0.54 & 2.33 & 2 & 2 & 0.88 & 0.40 & 0.35 \\
\hline K4 & 4.16 & 4 & 4 & 0.92 & 0.22 & 0.18 & 2.97 & 2 & 2 & 1.45 & 0.41 & 0.81 \\
\hline K5 & 4.04 & 4 & 5 & 1.07 & 0.26 & -0.90 & 3.12 & 4 & 4 & 1.40 & 0.38 & -0.75 \\
\hline K6 & 4.23 & 4 & 5 & 0.86 & 0.20 & -0.89 & 2.93 & 2 & 2 & 1.32 & 0.39 & 0.81 \\
\hline K7 & 3.99 & 4 & 5 & 1.03 & 0.26 & -0.98 & 3.04 & 3 & 2 & 1.42 & 0.39 & 0.87 \\
\hline
\end{tabular}

Abbreviations used: MDN - median, SD - standard deviation, CV - coefficient of variation, and SK - skewness

In order to answer RQ9 (Are there statistically significant differences in knowledge about products that Poland and UK based prosumers would like to share?), the Mann-Whitney U test 
was used since there are two independent samples: (a) Poland, and (b) UK based prosumers. The test results presented in Table 8 show that there were significant differences for all analyzed items. Thus, H3 is supported.

Table 8: The Mann-Whitney U Test Results for Knowledge About Products That Poland and UK Based Prosumers Would Like to Share

\begin{tabular}{|c|l|c|c|}
\hline Item & Types of Knowledge Would like to Share & $\mathbf{Z}$ & p value \\
\hline K1 & New product design & 6.470 & $<0.05$ \\
\hline K2 & Materials from which the product was made & 7.012 & $<0.05$ \\
\hline K3 & Package or graphic elements of the product & 10.298 & $<0.05$ \\
\hline K4 & Product functionality & 10.875 & $<0.05$ \\
\hline K5 & Reliability and durability of the product & 8.868 & $<0.05$ \\
\hline K6 & Ease and intuitiveness of product use & 12.171 & $<0.05$ \\
\hline K7 & Product performance & 8.966 & $<0.05$ \\
\hline
\end{tabular}

It was decided to perform a detailed analysis of knowledge about products that Poland and UK based prosumers would like to share as our intention was to draw a complete picture in that matter. The analysis was made using box plots. The results are presented in Figure 4.
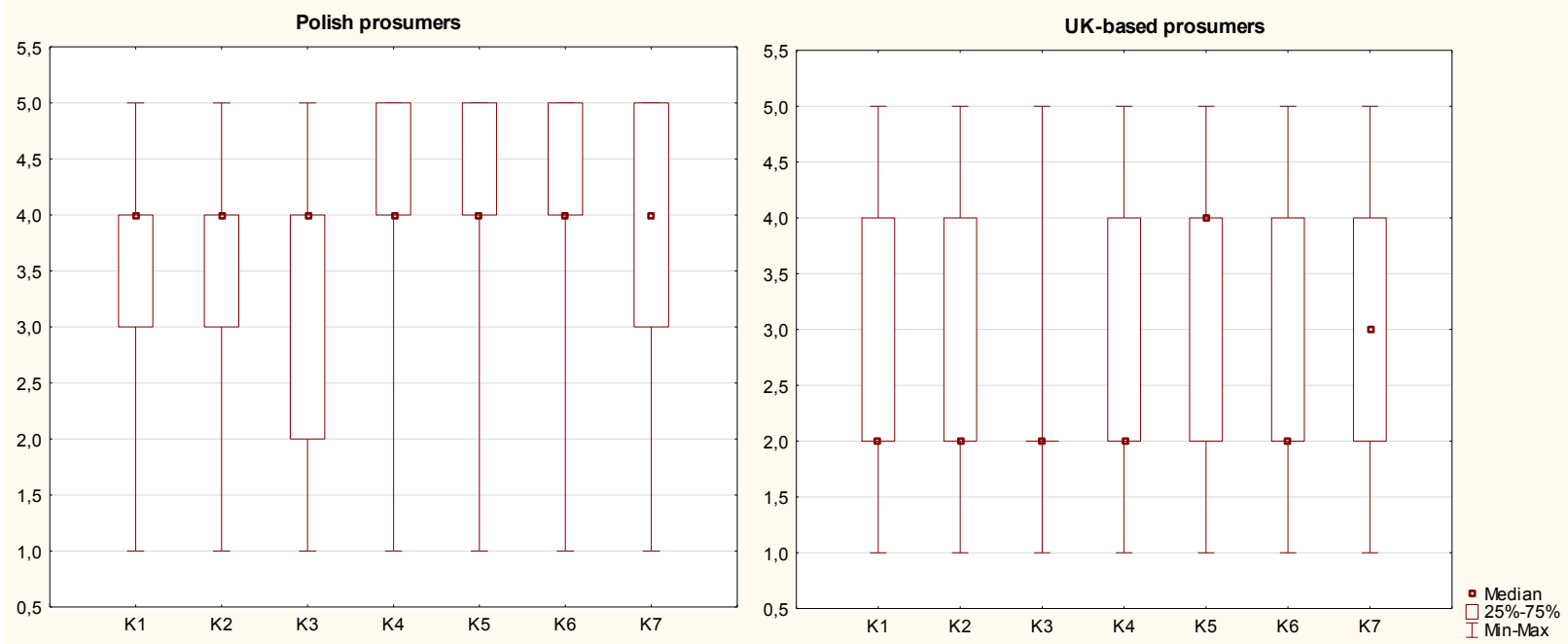

Figure 4: Knowledge About Products That Poland and UK Based Prosumers Would Like to Share

The box plots presented in Figure 4 show that:

- There were median differences between countries for all analyzed items, except reliability and durability of the product.

- In general, the values (median, first quartile $25 \%$, third quartile $75 \%$, as well as minmax) for Poland prosumers are higher than these values for UK based prosumers.

- In cases of product functionality, reliability and durability of the product, and ease and intuitiveness of product use the majority of Poland prosumers' answers were from 4 to 5 . It suggests that they would like to share knowledge. UK based prosumers are rather 
reluctant to share knowledge, except for reliability and durability of the product, when the median value is the highest and is equal to 4 .

\section{Discussion of Research Findings}

The business environment has embedded Web 2.0 into their marketing strategy and use social media technologies to capture customers' views, opinions, and early discussions to inform branding and promotional marketing. These tools are important in the bi-directional communication strategy for enhanced prosumer engagement. Further, the educational status of the prosumers tends to be high as indicated in these results and they tend to be heavy technology users (Gerhardt, 2008). The survey responses lead to three research hypotheses formulated and statistically tested. Using the data for Mann-Whitney U test, we were able to show support or non-support for the hypotheses and the results indicated that all three hypotheses were supported. The knowledge sharing process has been categorized to identify distinctive types of knowledge that provides opportunities for business to improve understanding of their customers input into the product development process/cycle (Lee et al., 2006).

This study supports the need for business to recognize the knowledge expected to be shared by prosumers to ensure improved knowledge sharing capabilities and improved engagement with customers. Businesses focus on the market, more particularly the needs of the market, should recognize the results of this study that reports on the role prosumers play in creating value for better as well as improved knowledge sharing about products and services currently on the market or those in the product life cycle. The results compared the prosumers current sharing of knowledge to future willingness to share knowledge with businesses. Box plots for all questions showed that half the scores in a distribution are between the hinges, and this suggests that Polish prosumers engage in sharing all kinds of knowledge during the product cycle; K1,K2, K3, K4, $\mathrm{K} 5$, K6, and K7. Whereas UK-based prosumers are less engaged in sharing knowledge than Polish prosumers in $\mathrm{K} 1, \mathrm{~K} 2$, K4, but slightly more engaged in $\mathrm{K} 5$ and are similarly engaged in K7. This suggests that engaging prosumers from Poland and UK in sharing knowledge about product performance will generate new ideas and should be considered more carefully in the product life cycle. The results also clearly showed that UK-based prosumers do not wish to share knowledge in K3 while Poland prosumers do so (Table 7). This indicates an interesting country specific preference from the prosumers groups (Hafkesbrink \& Evers, 2010). Furthermore, the results indicate the types of knowledge generated by consumers that feed back into the upstream activities (Piller, 2008) and the downstream activities (Hafkesbrink \& Schroll, 2010), while these activities on the part of the prosumers are largely non technical they are valuable in supporting the perceived needs of the market.

In terms of the prosumers willingness to engage in knowledge sharing in the future the box plots for all questions showed that half the scores in a distribution are between the hinges showing that the majority of responses from Poland prosumers suggest they are more interested in sharing all kinds of knowledge about products in the future. However, it is worth noting that $\mathrm{K} 3$ is relatively lower (Table 6) in terms of preference for the future and this is a potential indicator of the relative importance that may be placed on different kinds of knowledge sharing by Poland prosumers. Importantly other studies report on prosumer engagement in providing feedback on products and services that are already on the market (Piller, 2008). However, this study reports on prosumers willingness to provide feedback on preferences for products and services while 
they are still in the early stages of the product life cycle. This study also suggests that K4, K5, $\mathrm{K} 6$ and $\mathrm{K} 7$ are areas where the product cycle needs careful attention to align and encourage prosumers future knowledge sharing interests. The results clearly show that the UK based consumers who shared knowledge about product performance (K7), in the past are less inclined to share knowledge about product performance in the future. This suggests that there is a need for more refined and focused use of customer engagement and feedback tactics to ensure customer engagement in this nuanced part of the product cycle (Huang et al., 2016). To speculate this may be perhaps because product performance is viewed in the UK as one of the primary drivers for business in competitive markets. There are major differences between Poland and UK consumers and these differences are being observed in $\mathrm{K} 6$ and $\mathrm{K} 4$ followed by $\mathrm{K} 3$. The UK economy has historically been more consumer rich than the Poland economy and so the UK consumers may well be more settled with regard to ease and intuitiveness of product use (K6) and product functionality (K4) than their Poland counterparts for whom consumer acquisitions of certain ranges of products is still a relatively recent and newly developing feature, and for whom it might be understandable that a higher priority is placed upon these fundamental important factors determining why a product is bought. Similarly it may well be a perception on the part of the UK prosumers that packaging and graphic elements (K3) are much more settled issues. However, these results should be treated with caution because there are evidently wide differences between different industrial sectors even within the UK.

There was a clear indication that only one kind of knowledge sharing was a preference for UK based prosumers in the future, that being reliability and durability of the product (K5). The contribution of collaborators in sharing in communities of knowledge was reported by Groh et al. (2010), where they identified that participation may be strengthened by offering incentives as part of community engagement and knowledge sharing. Therefore, incentives may encourage more preferences for knowledge sharing from UK based prosumers in the future. This indicates another interesting country specific preference from the prosumers (Hafkesbrink \& Evers, 2010). The findings in this study point to the choices businesses need to make in gauging the types of knowledge that are important in the product and service life cycle development processes and align with those areas where prosumers can engage most often and as a consequence for both parties to gain the most benefits.

\section{Summary and Conclusions}

\section{Research Contribution}

This work contributes to extant research on prosumers engagement in knowledge sharing by:

- Indicating the cultural knowledge sharing differences between prosumers in countries such as Poland and UK

- Addressing the types of knowledge that Poland prosumers share and are willing to share in the future

- Addressing the types of knowledge that UK based prosumers share and are willing to share in the future

- Identifying significant association between types of knowledge preferences of Poland prosumers that are positively part of the development process and a limited types of 
knowledge that UK based prosumers would engage in the development process with enterprises in the future.

This work contributes to existing research on prosumption, especially prosumers' willingness to share knowledge. The specific kinds of knowledge identified in this study relate to the APQC Process Classification Framework (APQC, 2016). Consequently, indicating where the primary focus should be to align prosumer knowledge sharing with product processes to optimise intangible assets. It was interesting in this study that UK based prosumers did not regard engaging in discussions about product packaging elements of the product as useful whereas Poland prosumers saw value in this and strengthened collective ties with enterprises and customers. A second result appears that prosumers expectations vary depending on the types of knowledge offered to them by the enterprises. However, this may be related to how well the interaction is rewarded and managed.

\section{Implication for Research and Practice}

This study can be useful for researchers and practitioners. Researchers may use this methodology and do similar analyses with different samples in Poland, the UK, and other countries, additionally many comparisons between different groups and countries can be made. Moreover, the methodology constitutes a very comprehensive basis for identifying the types of knowledge that can encourage prosumers to engage in knowledge sharing, but researchers may develop, verify and improve this methodology and its implementation. In addition, researchers may use these research findings and employ them in studies of enterprises. Furthermore, for practitioners, the results of this study can be used to target the types of knowledge that align closely to the business product processes and optimise the decision outputs gained through knowledge sharing.

\section{Limitation and Future Research}

This study also has some limitations. The selection of survey respondents needs to be considered in light of the results, as they indicated that the majority of the respondents were young individuals below 35 year in Poland. In this case it is advisable to extend the research study to widen the age participation, and it would be useful to broaden the study to research elderly individuals, such as prosumers above age 50 years. A second limitation relates to the methodology approach. The current study considered prosumer's only rather than broadening the study to include enterprises. An intention will be to include enterprises in a further study. A third limitation relates to bias, as the original survey was designed in Polish and translated into English there may be some issues to address regarding the technical language which may be viewed as complex or consisting of uncommon words which then affect how the respondent's interpret the question. A pilot questionnaire was completed in the UK and questions were amended, and the vertical response scale was used to provide lists of response options as this reduces confusion from respondents. However, translation often results in a language bias that may affect the results. Further research will address the effect of common language where technical jargon can be reworded and sentences rephrased so as to limit the nature of ambiguous questions. The final limitation relates to the scope of the study, as the present study identifies only prosumers' knowledge that can be used to improve one of the main business processes, i.e. Develop and Manage Products and Services. A further study would attempt to conduct a more in-depth assessment on prosumers' knowledge related to other business processes. 


\section{References}

Aghamirian, B., Dorri, B., \& Aghamirian, B. (2013). Effects of customer knowledge management's eight factors in e-commerce. Management Science and Engineering, 7(4), $1-11$.

APQC. (2016). Process classification framework [online]. Houston: American Productivity and Quality Center. Retrieved from http://www.apqc.org/pcf

Brabham, D. C. (2012). Motivations for participation in a crowdsourcing application to improve public engagement in transit planning. Journal of Applied Communication Research, 40(3), 307-328.

Bylok, F. (2013). Konsumpcja, konsument i społeczeństwo konsumpcyjne we współczesnym świecie [Consumption, the consumer and the consumer society in the modern world]. Katowice: Śląsk.

Calosci, A. (2017). Places, communities and knowledge. You'll be part of an upcoming exhibition. The Design Journal, 20(1), 3393-3400. https://doi.org/10.1080/ 14606925.2017.1352843

Chesbrough, H.W. (2006). Open innovation: The New Imperative for Creating and Profiting from Technology. Harvard Business Press.

Cui, A.S., \& Wu, F. (2015). Utilizing customer knowledge in innovation: antecedents and impact of customer involvement on new product performance. Journal of the Academy of Marketing Science, 3, 1-23. https://doi.org/10.1007/s11747-015-0433-x

De Long, D.W. (1997). Building the knowledge-based organisation: How culture drives knowledge behaviors. Boston, MA: Center for Business Innovation, Ernst \& Young LLP.

Fine, M.B., Gironda, J., \& Petrescu, M. (2017). Prosumer motivations for electronic word-ofmouth communication behaviors. Journal of Hospitality and Tourism Technology, 8(2), 280-295. https://doi.org/10.1108/JHTT-09-2016-0048.

Geri, N., Gafni, R., \& Bengov, P. (2017). Crowdsourcing as a business model: extrinsic motivations for knowledge sharing in user-generated content websites. Journal of Global Operations and Strategic Sourcing 10(1), 90-111. https://doi.org/10.1108/JGOSS-052016-0018

Gerhardt, W. (2008). Prosumers: A new growth opportunity. Cisco Internet Business Solutions Group (IBSG). Cisco Systems, Inc.

Glisby, M., \& Holden, N. (2003). Contextual constraints in knowledge management theory: the cultural embeddedness of Nonaka's knowledge-creating company. Knowledge and Process Management, 10(1), 29-36.

Gold, A. H., Malhotra, A., \& Segars, A.H. (2001). Knowledge management: An organizational capabilities perspective. Journal of Management Information Systems, 18(1), 185-214.

Groh, G., Brocco, M., \& Asikin, Y.A. (2010). Contribution awareness and fame in open innovation network’s. In Hafkesbrink, J., Hoppe, H.-U., \& Schlichter, J. (eds.), 
Competence Management for Open Innovation - Tools and IT-support to unlock the potential of Open Innovation, pp. 115-138. Lohmar-Koln: Josef Eul Verlag.

Hafkesbrink, J., \& Evers, J. (2010). Innovation 3.0: Embedding into community knowledge The relevance of trust as enabling factor for collaborative organizational learning. Proceedings of the XXI ISPIM Conference Bilbao, The Dynamics of Innovation.

Hafkesbrink, J., \& Schroll, M. (2010). Organizational competences for open innovation in small and medium sized enterprises of the digital economy'. In Hafkesbrink, J., Hoppe, H.-U., \& Schlichter, J. (eds.), Competence management for open innovation - tools and ITsupport to unlock the potential of Open Innovation, pp. 21-52. Lohmar-Koln: Josef Eul Verlag.

Hernández-Serrano, M.J., Renés-Arellano, P., Graham, G., Greenhill, A. (2017). From prosumer to prodesigner: Participatory news consumption. Comunicar, 25(50), 77-87.

Hinton, P. (2004). Statistics explained: A guide for social science students. New York, NY: Routledge.

Huang, N., Burtch, G., Hong, Y., \& Polman, E. (2016). Effects of multiple psychological distances on construal and consumer evaluation: A field study of online reviews. Journal of Consumer Psychology, 26(4), 474-482. https://doi.org/10.1016/j.jcps.2016.03.001

Kania, K. (2012). Doskonalenie zarzadzania procesami biznesowymi w organizacji z wykorzystaniem modeli dojrzałości i technologii informacyjno-komunikacyjnych [Business processes management improving with employing of majority frameworks and ICT]. Katowice: University of Economics Publishing House.

Kayworth, T., \& Leidner, D. (2003). Organizational culture as a knowledge resource. In: C.W. Holsapple (Ed.), Handbook on Knowledge Management, 1, pp. 235-252. Berlin: Springer.

Löcker, A.K., Eraßme, D., Jakobs, E.M., Schaar, A.K., Valdez, A.C., \& Ziefle. M. (2014). Yet another platform? Motivational factors for using online communities in business contexts. Proceedings of the 5th International Conference on Applied Human Factors and Ergonomics AHFE 2014, pp. 1145-1156. 19-23 July 2014, Krakow, Poland.

Nonaka, I., \& Takeuchi, H. (2000). Kreowanie wiedzy w organizacji [Knowledge creation in organizations]. Warszawa: Poltext Press.

Piller, F. (2008). Interactive value creation with users and customers. Retrieved from http://www.mass-customization.de/download/piller_2008-pribilla.pdf.

Planells, A.J. (2015). Video games and the crowdfunding ideology: From the gamer-buyer to the prosumer-investor. Journal of Consumer Culture, 17(3), 620-638. https://doi.org/10.1177/1469540515611200

Rayna, T., \& Striukova, L. (2016). Involving consumers: The role of digital technologies in promoting 'prosumption' and user innovation. Journal of the Knowledge Economy [Open Access], 1-20. https://doi.org/10.1007/s13132-016-0390-8 
Ritzer, G., \& Jurgenson, N. (2010). Production, consumption, prosumption: The nature of capitalism in the age of the digital 'prosumer'. Journal of Consumer Culture, 10(1), 13-36.

Song, E.-J., \& Kang, M.-S. (2016). A study on the platform of knowledge integration for customer feedback in B2C service industry. International Journal of Information and Communication Technology, 8(1), 26-36. https://doi.org/10.1504/ ijict.2016.073637

Taherparvar, N., Esmaeilpour, R., \& Dostar, M. (2014). Customer knowledge management, innovation capability, and business performance: A case study of the banking industry. Journal of Knowledge Management, 3(18). Retrieved from http://www.emeraldinsight.com/journals.htm?issn=1367-3270\&volume=18\&issue=3

Tapscott, D., \& Williams, A.D. (2006). Wikinomics: How mass collaboration changes everything. New York, NY: Penguin Group.

Trejo, J.M., Gutiérrez, J.S., \& Guzman, G.M. (2016). The customer knowledge management and innovation. Contaduría y Administración, 61(3), 456-477. https://doi.org/ 10.1016/j.cya.2015.11.011

Tsai, W., Tsai, M., Li, S., \& Lin, C. (2012). Harmonizing firms' knowledge and strategies with organizational capabilities. Journal of Computer Information Systems, 53(1), 23-32.

Tseng, S.-M. (2016). The effect of knowledge management capability and customer knowledge gaps on corporate performance. Journal of Enterprise Information Management, 29(1), 51-71. doi: 10.1108/JEIM-03-2015-0021

Walsh, J. P. Lee, Y.-N., \& Nagaoka, S. (2016). Openness and innovation in the US: Collaboration form, idea generation and implementation. Research Policy, 45(8), 1660 1671. doi: 10.1016/j.respol.2016.04.013

Xie, C., Bagozzi, R.P., \& Troye, S.V. (2008). Trying to prosumer: Toward a theory of consumers as co-creators of value. Journal of the Academy of Marketing Science, 36, 109-122.

Ziemba, E., Eisenbardt, M. (2017). Utilization of consumers' knowledge in organizations. In F. Marimon, M. Mas-Machuca, J. Berbegal-Mirabent, R. Bastida, (Eds.), Proceedings of the 18th European Conference on Knowledge Management ECKM 2017, 2, pp. 10841093. Barcelona, International University of Catalonia, September 7-8, 2017.

Ziemba, E., Eisenbardt, M., \& Mullins, R. (2017). Use of Information and Communication Technologies for Knowledge Sharing by Polish and UK-Based Prosumers. In Ziemba E. (ed.), Information Technology for Management: New Ideas and Real Solutions. Lecture Notes in Business Information Processing, 277, 49-73. Switzerland: Springer. DOI: 10.1007/978-3-319-53076-5_4

Ziemba, E. \& Mullins, R. (2016). Identifying more about customers: the phenomenon of the switch to the knowledge exchange. Online Journal of Applied Knowledge Management, $4(1), 165-179$.

Ziemba, E., \& Eisenbardt, M. (2015). Prosumers' participation in business processes. Online Journal of Applied Knowledge Management, 3(1), 114-127. 
Ziemba, E., \& Eisenbardt, M. (2015a). Examining prosumers participation in business processes. Polish Journal of Management Studies, 12(1), s. 219-229.

\section{Authors' Biographies}

Ewa Ziemba completed her Ph.D. and Post Ph.D. in Management, with a major focus on management information systems. She is an Associate Professor at the University of Economics, Katowice, Poland. Her current research focuses on information systems and technologies for business and public administration transformation. She has published over 170 peer-reviewed papers and 18 books, and has played an instrumental role in prestigious Polish and international research projects. Ewa Ziemba serves on the editorial boards of several international journals, is the Founding Editor-in-Chief of The Online Journal of Applied Knowledge Management, the Editor-in-Chief of Journal of Economics and Management, and the Editor of Interdisciplinary Journal of Information, Knowledge, and Management. She is also the Vice President for Research Collaborations of the International Institute for Applied Knowledge Management. Ewa Ziemba has received numerous awards for research and teaching, including The Excellent Award of the President of the University of Economics in Katowice, The Silver Cross of Merit from the President of Poland, The Medal of the National Education Commission from the Ministry of National Education in Poland, The Award of Fellow \& Distinguished Scholar and The Excellence in Research \& Scholarship Award from the International Institute for Applied Knowledge Management, and several The Best Papers awards.

Monika Eisenbardt completed her Ph.D. with a major focus on management information systems as well as changes and challenges involving modern consumers. She is an Assistant Professor at the University of Economics in Katowice, Poland. She has published over 30 peerreviewed pieces including conference papers, book chapters and international journal papers. She has received few Best Paper awards at the international conferences. Her current research focuses on consumers' knowledge and their willingness to knowledge sharing, as well as knowledge-based organizations. The background of her research is information and communication technologies. Monika serves Editorial Assistant function in Journal of Economics and Management - the official international journal of University of Economics in Katowice. She has received several Best Paper awards at the international conferences.

Roisin Mullins completed her Ph.D. in the development and evaluation of e-learning systems, learning communities and business training systems. She has published over 50 peer-reviewed pieces including conference papers, book chapters and international journal papers. Roisin Mullins serves on the editorial boards of several international conferences. Her research has emphasized practical solutions to technology problems or novel applications of technology, so that in addition to answering a question, the research outcomes have informed policy and practice guidelines at the European level and decision making processes in the SMEs of EU member countries. She has received several Best Paper awards at the international conferences.

Dariusz Grabara is a Ph.D. student. He completed his MSc. with strong focus on the computer market analysis and prognostic models for desktop computer prices. He is an Assistant at the University of Economics, Katowice. His current research is aimed at the electronic auction platforms with focus on determining crucial variables, which affect sellers' behaviour. He has gained experience during his work for IT companies, banks, and automation industry. 